\title{
Synthesis of 2-Propoxy-5-Methylbenzoic Acid ${ }^{1}$ \\ Gerhard M. Brauer and Lester Simon
}

(April 3, 1962)

\begin{abstract}
2-Propoxy-5-methylbenzoic acid has been synthesized by two routes from $p$-cresotinic acid. Synthesis of the ethyl ester of $p$-cresotinic acid, propylation to the ether, and subsequent hydrolysis of the ester proved to be the preferred route.
\end{abstract}

\section{Introduction}

The reactivity of various chelating agents with zinc oxide has been investigated in the course of work on the development of improved dental cements [1]. ${ }^{2}$ For this investigation there was needed an unsymmetrically disubstituted benzoic acid derivative that is liquid at room temperature.

From the few compounds that meet these specifications, 2-propoxy-5-methylbenzoic acid was selected. 1 The research work was supported under an Office of Naval Research grant-
contract ONR P. J.-NR 105-210.

2 Figures in brackets indicate the literature references at the end of this paper.
This compound has been reported [2] in a study of the effect of various alkoxy groups on the anomalous reactivity of $o$-alkoxyphenylmagnesium bromide Grignard reagents with carbon dioxide.

The synthetic route employed by Holmberg [2] in obtaining 2-propoxy-5-methylbenzoic acid did not appear to be well adapted for the preparation of the quantity needed because of the unavailability of the required intermediates as well as the formation, as a byproduct in the Grignard reaction, of a large amount of $2,2^{\prime}$-dipropoxy-5, $5^{\prime}$-dimethylbenzophenone. Two other routes shown in figure 1 were therefore investigated; the second avoided tedious separation of intermediate products and gave a better yield.

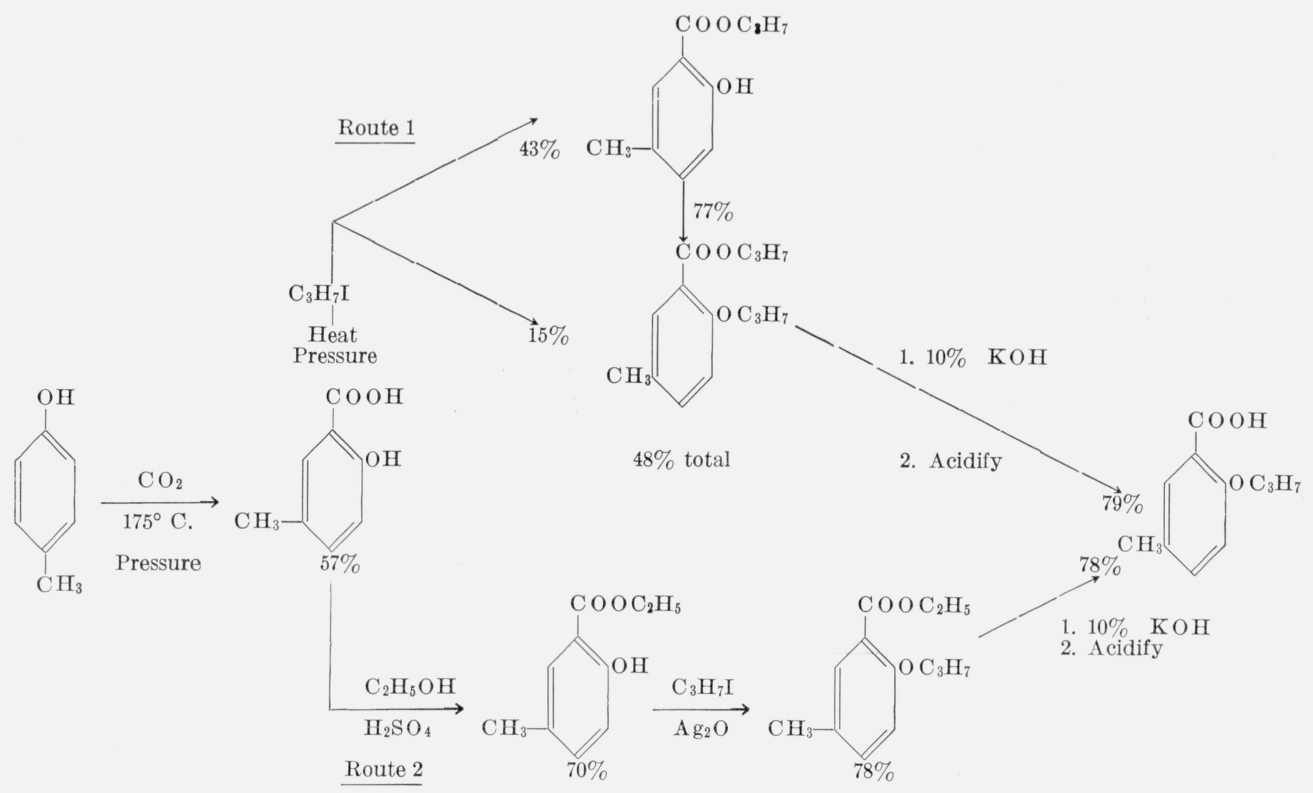

FIGURE 1. Synthesis of 2-propoxy-5-methylbenzoic acid.

( $38 \%$ overall yield by route $1,43 \%$ overall yield by route 2 , based on $p$-cresotinic acid) 


\section{Experimental Procedure}

\subsection{Preparation of $p$-Cresotinic Acid}

$p$-Cresotinic acid (2-hydroxy-5-methylbenzoic acid) was prepared by carbonation of $p$-cresol according to the procedure of Cameron, Jeskey, and Baine [3]. Dry, powdered potassium cresoxide was placed in a pressure bomb and carbon dioxide was admitted until a pressure of 10 atm was obtained. The bomb was heated for $24 \mathrm{hr}$ at $175^{\circ} \mathrm{C}$ and cooled; the material was then purified as described by Cameron et al.

\subsection{Synthesis of 2-Propoxy-5-Methylbenzoic Acid (Route 1)}

\section{a. Propylation of $p$-Cresotinic Acid}

In an $800-\mathrm{ml}$ pressure bomb, a mixture of 52.9 g (0.35 mole) of $p$-cresotinic acid, $42 \mathrm{~g}$ (0.75 mole) of $\mathrm{KOH}$, and $122 \mathrm{~g}$ (0.72 mole) of $n$-propyl iodide was heated overnight at $145{ }^{\circ} \mathrm{C}$. The reaction mixture was dissolved in hot water, the solution was extracted with ether, and the ether solution was shaken with 5 percent aqueous $\mathrm{NaOH}$. After evaporation of the ether, $45.0 \mathrm{~g}$ of liquid remained. Vacuum distillation of the residue gave two fractions.

Fraction 1, propyl 2-hydroxy-5-methylbenzoate, distilled at $77-79{ }^{\circ} \mathrm{C} / 4 \mathrm{~mm}$ as a colorless liquid, bp 266-268 ${ }^{\circ} \mathrm{C}, \mathrm{n}_{\mathrm{D}}{ }^{25} 1.5122$, which gave a positive ferric chloride test for phenol.

Yield: $28.9 \mathrm{~g}(43 \%)$.

Anal: Calcd. for $\mathrm{C}_{11} \mathrm{H}_{14} \mathrm{O}_{3}$ : Found ${ }^{3}$ :

C, $68.02 ; \mathrm{H}, 7.27$.

$\mathrm{C}, 68.2 ; \mathrm{H}, 7.4$.

Infrared spectrum ${ }^{4}$ : Absorption bands at the respective wavelengths indicate the presence of the following groups [4,5]: $3.16 \mu$, hydroxyl; $5.95 \mu$, ester carbonyl for salicylates; doublet at $6.15 \mu$ and $6.24 \mu$, possible conjugation of the carbon-oxygen double bond with aromatic ring; $8.30 \mu$, phenol; and $12.11 \mu$, unsymmetrically trisubstituted benzene.

Fraction 2, propyl 2-propoxy-5-methylbenzoate, distilled at $100-108{ }^{\circ} \mathrm{C} / 4 \mathrm{~mm}$ as a colorless liquid, bp $302{ }^{\circ} \mathrm{C}, \mathrm{n}_{\mathrm{D}}{ }^{28} 1.5022$, which gave negative tests with ferric chloride, 'Tollens' reagent, and 2,4dinitrophenylhydrazine.

Yield: $12.2 \mathrm{~g}(15 \%)$

Anal: Calcd. for $\mathrm{C}_{14} \mathrm{H}_{20} \mathrm{O}_{3}$ : $\quad$ C, $71.16 ; \mathrm{H}, 8.53$. Found:

C, $70.6 ; \mathrm{H}, 8.4$.

Infrared spectrum: The presence of the following groups is indicated: benzoyl, alkoxy, and unsymmetrically trisubstituted benzene.

The propyl ester of $p$-cresotinic acid (fraction 1) was converted to the propoxy ether as follows: A solution of sodium ethoxide, prepared from $2.8 \mathrm{~g}$ (0.125 equivalent) of sodium and $60 \mathrm{ml}$ of absolute

3 Carbon and hydrogen analyses were done by E. Deardorff of the -Standard Reference Materials Section, National Bureau of Standards.

4 Infrared spectra were determined by Miss M. Katharyn Wharton, Applied Polymer Standards and Research Section, National Bureau of Standards. ethanol, and an excess (27.0 g, 0.159 mole) of propyl iodide were added to $24.2 \mathrm{~g}(0.125$ mole) of the ester. The solution was refluxed until it was no longer alkaline to litmus. After evaporation of the ethanol under reduced pressure, the residue was dissolved in ether, and the solution was extracted with 5 percent aqueous $\mathrm{NaOH}$. On concentration of the ether solution, there remained $22.7 \mathrm{~g}(77 \%)$ of propyl 2-propoxy-5-methylbenzoate, which, when purified by vacuum distillation, was identical in boiling point, $\mathrm{n}_{\mathrm{D}}$, and infrared absorption with fraction 2 .

\section{b. Hydrolysis of Propyl 2-Propoxy-5-Methylbenzoate}

Ten grams of the sample in $35 \mathrm{ml}$ of a 10 percent solution of $\mathrm{KOH}$ in 50 percent aqueous ethanol were refluxed for $4 \mathrm{hr}$, and the ethanol and propanol were removed by distillation. The residue was acidified with $\mathrm{HCl}$ and extracted with ether, and the ether extract was concentrated by evaporation. Vacuum distillation of the residue at approximately $4 \mathrm{~mm}$ yielded $6.5 \mathrm{~g}(79 \%)$ of 2-propoxy-5-methylbenzoic acid, bp $257{ }^{\circ} \mathrm{C}, \mathrm{n}_{\mathrm{D}}{ }^{27}$ 1.527. Infrared spectrum confirmed the presence of $-\mathrm{OH}, \mathrm{COOH}$, ether, and unsymmetrically trisubstituted benzene groups.

\subsection{Synthesis of 2-Propoxy-5-Methylbenzoic Acid (Route 2)}

In order to avoid the tedious separation of the products of the propylation of 2-hydroxy-5-methylbenzoic acid, an improved synthesis of 2-propoxy5 -methylbenzoic acid was developed. The $p$-cresotinic acid is converted to the ethyl ester which is allowed to react with propyl iodide. The resulting ethyl 2-propoxy-5-methylbenzoate on hydrolysis gives 2-propoxy-5-methylbenzoic acid.

\section{a. Ethyl 2-Hydroxy-5-Methylbenzoate}

$p$-Cresotinic acid (13 g, 0.085 mole) was refluxed for $8 \mathrm{hr}$ with $39 \mathrm{ml}(0.67$ mole $)$ of absolute ethanol and a few milliliters of concentrated $\mathrm{H}_{2} \mathrm{SO}_{4}$ as a catalyst. The excess ethanol was distilled, and the ester was successively washed with water and 5 percent aqueous $\mathrm{NaHCO}_{3}$, dried over anhydrous $\mathrm{Na}_{2} \mathrm{SO}_{4}$, and distilled at 94 to $95{ }^{\circ} \mathrm{C} / 4 \mathrm{~mm}$. The liquid had a boiling point of $235{ }^{\circ} \mathrm{C}, \mathrm{n}_{\mathrm{D}}{ }^{25}=1.5190$.

Yield: $10.8 \mathrm{~g}(70 \%)$.

Anal: Calcd. for $\mathrm{C}_{10} \mathrm{H}_{12} \mathrm{O}_{3}$ : C, $66.7 ; \mathrm{H}, 6.73$.

$$
\text { Found: } \quad \text { C, 66.9; H, 7.0. }
$$

Infrared spectrum: The principal bands are the same as those for the propyl ester.

\section{b. Ethyl 2-Propoxy-5-Methylbenzoate}

A solution of $10.8 \mathrm{~g}$ ( 0.06 mole) of the ethyl ester $\mathrm{n} 21.6 \mathrm{~g}$ of benzene was refluxed overnight in the presence of $21.0 \mathrm{~g}$ of freshly precipitated, dry silver oxide and $32.4 \mathrm{~g}$ (0.19 mole) of propyl iodide. The liquid was decanted from the remaining solid, and the benzene was distilled off. The residue was extracted with ether, and the ether solution washed with 10 percent $\mathrm{NaOH}$ and dried. The liquid remaining after evaporation of the solvent distilled at $133^{\circ} \mathrm{C} / 6 \mathrm{~mm}$ 
The colorless liquid decomposed before reaching the boiling point, $\mathrm{n}_{\mathrm{D}}{ }^{27}=1.5033$.

Yield: $10.4 \mathrm{~g}(78 \%)$.

Anal: Calcd. for $\mathrm{C}_{13} \mathrm{H}_{18} \mathrm{O}_{3}:$ C, $70.3 ; \mathrm{H}, 8.16$.
$\begin{array}{ll}\text { Found: } & \text { Co.3; H, 8.1. }\end{array}$

Infrared spectrum: The spectrum is very similar to that of the propyl ester. All absorption bands occur at approximately the same wavelengths as those found for the propyl ester.

c. Hydrolysis of Ethyl 2-Propoxy-5-Methylbenzoate

The procedure is similar to that described in route 1 for the hydrolysis of the propyl ester; $7.3 \mathrm{~g}$ of the ethyl ester was refluxed for $8 \mathrm{hr}$ with 10 percent $\mathrm{KOH}$ in 50 percent ethanol.

Yield of purified product: $5.0 \mathrm{~g}(78 \%), \mathrm{n}_{\mathbf{D}}{ }^{27}=1.5269$.

Anal: Calcd. For $\mathrm{C}_{11} \mathrm{H}_{14} \mathrm{O}_{3}$ : C, $68.0 ; \mathrm{H}, 7.3$.

Found:

C, $67.9 ; \mathrm{H}, 7.5$.

The infrared absorption spectra of the products obtained by routes 1 and 2 were identical.
The authors thank R. S. Tipson for valuable suggestions.

\section{References}

[1] Brauer, G. M., White, E. E., and Moshonas, M. G., J. Dental Res. 37, 547 (1958).

[2] Holmberg, G. A., Acta Chem. Scand. 10, 594 (1956).

[3] Cameron, D., Jeskey, H., and Baine, O., J. Org. Chem. 15, $233(1950)$.

[4] Spectra-structure correlation chart, The Perkin-Elmer Co., Norwalk, Conn.

[5] Bellamy, L. J., Infra-red Spectra of Complex Molecules, John Wiley \& Sons, New York (1954). 